DEDA ĐELOVIĆ, Ph.D.

E-mail: deda.djelovic@lukabar.me

The Port of Bar

Obala 13. Jula b.b., 85000 Bar, Republic of Montenegro

DIJANA MEDENICA MITROVIĆ, M.Sc.

E-mail: disan@t-com.me

Faculty for Business Management

Maršala Tita br. 7, 85000 Bar, Republic of Montenegro
Traffic Management

Review

Accepted: Apr. 21, 2009

Approved: May 17, 2010

\title{
AN APPROACH TO THE SELECTION OF OPTIMAL TRANSFORMATION STRATEGY IN SEAPORTS
}

\begin{abstract}
After theoretical considerations of organizational changes, the research findings were presented in relation to the following: the selection of the optimal model for implementation of organizational changes in the port that is subject of analysis and establishing of the character of the correlation between the organizational changes, the productivity level and the ship service time (components related to cargo handling operations). Through the implementation of AHP (Analytic Hierarchy Process) method, it has been identified that the optimal model for implementation of organizational changes in the studied port is restructuring. Starting from the relevant elements of the process model of productivity improvement, direct interdependency has been identified between the character of organizational changes and the level of productivity per full-time employee in the port, as well as the existence of correlation between the character of organizational changes, productivity level in the cargo handling process ship service time.
\end{abstract}

\section{KEY WORDS}

port, organisational changes, AHP method

\section{INTRODUCTION}

Contemporary organizations are placed in a very complex, unstable and dynamic environment. One of the basic tasks they are encountering is constant adapting to changes so as to provide for compatibility with the environment.

Organizational change implies only the change of such variables which make the content of an organization as a process [1], [2]. According to some authors an organizational change implies any change in the organization leading to a higher level of efficiency and effectiveness in functioning, including standards and methods of their measurement [3]. The following may be identified as the content of organisational changes [3], [4], [5]: changes in organizational structure (in- cluding implementation of the different organisational models and appropriate decision support systems), changes in management structure, changes in business processes, activities and tasks, changes in organizational systems, changes in technology, changes in organizational culture and changes in people.

Since organizations exist in a dynamic and very unstable environment, the concept of organizational development therefore does not meet all the needs of contemporary organizations. Thus, the concept of organizational transformation has been introduced, which interprets organizational changes in a different way in relation to the concept of organizational development. The concept of organizational transformations implies that dynamics of organizations consists of turns in periods of relative stability and balance, when the organization improves through incremental changes, and relatively short periods of misbalance when an organization fully alters through the process of radical changes.

Different authors define the organizational transformation in various ways. Thus, according to Collins and Porras organizational transformation implies "a group of theories, values, strategies and techniques of science of behaviour, focused on the planned change of the organizational vision and regulation of work, with the intention of generating alpha, beta, gamma $A$ and gamma $B$ changes in the awareness of the members of the organization, for the purpose of promoting paradigmatic changes which assist the organization to adapt to the existent or create a desirable future environment [6], [7]. The main feature of this definition is the one that insists on behaviourist content of the organizational transformation.

According to the definition given by Gouillart and Kelly [8], organizational transformation views the organization as a living organism, which due to serious deficiencies in itself, must initiate a complete "medical" treatment, and transformation should be initiated as a 


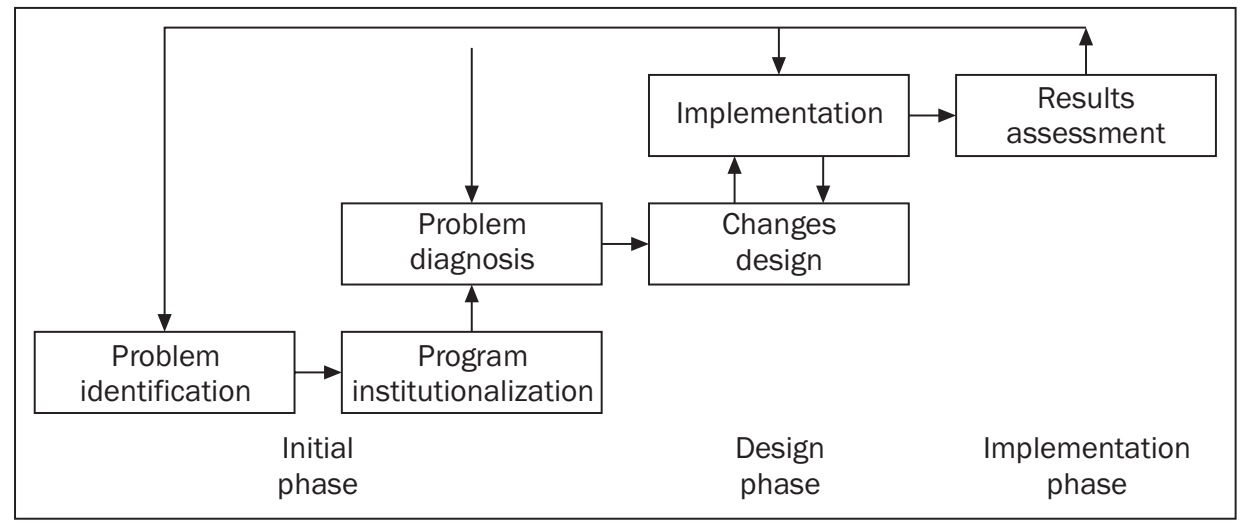

Figure 1 - Phases of the organizational transformation process [3]

radical and complete "therapy" which consists of: redirecting - change in the perception of what the organization is and what it may be; restructuring - changes in organizational structure; revitalization - achievement of growth through improvement of relations with the environment; renewal - change of the spirit of the organization, i.e. affecting the human factor in the organization through application of the model for development of personality and relations within the organization.

The process of organizational transformation is very complex and as in the case of other concepts of organizational changes, there is no universal model for its implementation. The model of organizational transformation, which is generally used, consists of the following phases: initial phase, design phase and implementation phase.

\section{ELEMENTS CONDITIONING THE NECESSITY FOR ORGANIZAITONAL CHANGES IN SEAPORTS}

In the circumstances characterized by intensification of exchange of goods, rapid development of science, technique and technology, problems to be resolved also change as well as the elements of the environment to which the port needs to adapt. Therefore, it is frequently necessary to also modify organizational structure of the port through improvement of the existent or introduction of a completely new one. Organizational model should fully respect the fact that traditional role of ports has significantly evolved and that ports are no longer selected only for their natural hinterland but for being the best centres for adding value to goods and nodes in overall transport chain of goods [9].

The process of selection of a port organizational model is complex and there is no perfect methodology for its implementation.

The process of improvement of the existent or introduction of a new organization model, or process of se- lecting the port organizational model, should be based on previously clearly defined goals to be achieved. Some from the group of main goals include: improvement of productivity, rationalization of port structure, orientation towards the processes for the purpose of creating the base for competitive positioning in the free market, attracting private capital, etc. After defining the goals, options and alternatives should be developed and assessed. Particularly, it is necessary to analyze the results arising from selecting any specific option. A useful instrument for planning the process of selecting the port organization model (selecting the optimal options) is the decision tree.

\section{FACTORS DETERMINING THE RESEARCH OF ORGANIZATIONAL CHANGES IN SEAPORTS}

\subsection{Object of research}

In order to achieve and reach the satisfying level of effectiveness and efficiency which guarantees seaports survival at the global level, it is necessary to introduce organizational changes that will ensure the above mentioned. Based on the previous statement and the consideration of findings referred to in sections 1 and 2, the following research object has been defined:

- selection of the optimal transformation strategy for the seaports;

- correlation between organizational changes and the value of performance indicators of the port operations (productivity level);

Research has been carried out in the real system - The Port of Bar

\subsection{Research objective}

The overall objective of the research includes the following components: defining of the optimal trans- 
formation strategy for the seaport being the subject of the research; establishing of the correlation between the organizational changes and the productivity level in the cargo handling process in the studied seaport; identification of parameters impacting the successfulness of implementation of organizational changes in the seaports.

\subsection{Hypotheses}

The key starting hypotheses of the research covered by this paper are as follows:

H1 - the optimal transformation strategy for the studied seaport is restructuring;

H2 - adequate implementation of organizational changes contributes to the increase of the productivity level in the port.

\subsection{Characteristics of the studied port}

Taking the basic structure of the WORKPORT model of transition in European ports [10], as a base, next Table (Table 1) gives the key performances of the Port of Bar as the object of analysis.

Table 1 - WORKPORT model - elements referred on the Port of Bar

\begin{tabular}{||l|l||}
\hline \hline Element & \multicolumn{1}{|c||}{ Current status in the Port of Bar } \\
\hline \hline $\begin{array}{l}\text { Owner- } \\
\text { ship }\end{array}$ & $\begin{array}{l}\text { The Port of Bar is a shareholding com- } \\
\text { pany. Majority of shares (54\%) are owned } \\
\text { by the Government of Montenegro. }\end{array}$ \\
\hline $\begin{array}{l}\text { Organi- } \\
\text { sational } \\
\text { structure }\end{array}$ & $\begin{array}{l}\text { Hierarchical organisational struc- } \\
\text { ture. Improved qualification structure } \\
\text { of the labour force. Increasing de- } \\
\text { mands for knowledge from the domain } \\
\text { of ICT. Focus on services quality. }\end{array}$ \\
\hline $\begin{array}{l}\text { Port } \\
\text { functions }\end{array}$ & $\begin{array}{l}\text { Cargo handling operations are dominant } \\
\text { (comparing their share in overall activities } \\
\text { with industrial and trade activities in the port } \\
\text { area). Port area is under Free Zone regime. }\end{array}$ \\
\hline ... & \multicolumn{2}{|l}{} \\
\hline \hline
\end{tabular}

\section{RESEARCH METHODOLOGY}

Researches covered by the paper have been carried out through the application of the following methods: AHP (Analytic Hierarchy Process) method for the selection of the optimal transformation strategy for the port being the subject of the analysis; elements of the Process model for improvement of the level of productivity in the cargo handling process; methods of mathematical statistics;

\subsection{AHP (Analytic Hierarchy Process) method}

Selection of the optimal transformation strategy can be realized implementing different models. Modern management theories suggest implementation of some of the methods for multi-criteria optimization such as TOPSIS, SAW, AHP etc. In a special manner, the implementation of AHP (Analytic Hierarchy Process) method is suggested [11], [12], [13]. The AHP method is a method of multi-criteria analysis [14] and it was presented for the first time in 1970. This method is very suitable for defining the problem and its analysis and, in general, considers decomposition of a complex situation, using holistic approach. The implementation of the AHP method considers the definition of the comparison criteria and different alternatives. In this model a group of alternative strategies is given which could be implemented in the process of a sea port transformation. These alternatives could be defined as follows [15]:

- A1 - quality programme - this alternative for the transformation considers activities directed to improving (maximizing) the quality of port services;

- A2 - changes in the domain of culture - refers on the organizational culture adaptability, which, to a very large extent, depends on the position of a port on the domestic and international market;

- A3 - design renewals - is related to renewals of the business process design through analyses of the existing and creating of necessary changes (improvements) in order to increase efficiency;

- A4 - restructuring - considers transformation of a port as a system from different points of view ownership structure, organizational structure, etc. Key objectives of this transformation are improving business performances, increasing degree of competitiveness and fulfilling the basic preconditions for making profit;

Selection of the optimal transformation strategy requires definition of relevant criteria for its realization. Starting from the previously identified strategic objectives, the following criteria for comparing (evaluating) strategies are chosen:

- K1 - port resources capability - this criterion respects the existing development level of services, human resources, available capital and other elements which are necessary for adjusting port functioning to the demands generated by external factors;

- K2 - making profit - in order to enable the development of the port it is necessary to implement business strategies which result in profit;

- K3 - competitiveness on the market - priorities in the process of transformation strategy selection are given to those criteria which enable adequate degree of competitiveness;

- K4 - orientation to clients - one of the crucially important criteria is respecting clients requirements. 
The port has to have a strategy for satisfying customers demands up to the optimal level;

- K5 - organizational culture - organizational culture refers to relations between employees, business image, etc. The common system of values enables knowledge transfer, improving quality of tasks realization, etc.;

- K6 - influence of the state authorities - this criterion refers to the influence of the state authorities through their influence on the market;

The software which enables computer use in the application of AHP method is Expert Choice [11], [12], [13]. Section 5.1 presents the results of the application of the mentioned software in the process of selecting one of the defined alternatives, based on the starting criteria. The application of methods implies the intercomparison of criteria, and then inter-comparison of alternatives in relation to each criterion.

\subsection{Process model of productivity improvement}

Based on the general form of the process model given in [16], here a model of productivity improving process is structured (Figure 2.). The presented model respects the fact that port machinery has the central role in achieving the required values of productivity in the cargo handling process. For the purpose of carrying out the research elements related to identifying effects of implemented organizational changes on the productivity level, particularly significant is the segment of model "4 - Measuring, analysis, improvements" which enables quantification of effects of previously implemented changes.

\section{RESEARCH RESULTS}

\subsection{Selection of the optimal transformation strategy implementing AHP method}

In the next section the results of the AHP method implementation (using software Expert Choice) for the selection of optimal transformation strategy of the selected port among the previously defined alternatives based on the adopted criteria are presented. Starting from an estimation (done by the authors) of the defined criteria importance, using Saaty's scale of comparison (Table 2) [11], a relative rank for all criteria is defined (Table 3). Then the index of consistency C.I. (its maximal value is 0.1 ) is defined. If C.I. $>0.1$ - it is recommended to correct some of the estimations, because the person who made these was inconsistent.

Based on the results shown in Table 3, it can be concluded that the criterion with the highest weight is: K2 - making profit. Comparing all alternatives from the aspect of all criteria, the following results were obtained (Table 4).

The best transformation strategy for the considered port, selected through the application of AHP method of multi-criteria analysis, is strategy A4 - Restructuring. Therefore, optimal transformation strategy is Restructuring and the basic criterion is making profit. In general, the set of objectives of the restructuring process includes the following elements, too: increase of the level of efficiency in the cargo handling process, reduction of costs of port services, finding new funding sources for development, introduction of modern management methods, resolving of redundancy issue, etc.

Table 2 - Comparison scale for AHP method [11]

\begin{tabular}{|c|l||}
\hline 1 & Equal importance of the criteria \\
\hline 3 & Slightly greater importance of the first criterion \\
\hline 5 & Greater importance of the first criterion in relation to the second one \\
\hline 7 & Much greater importance of the first criterion \\
\hline 9 & Extremely greater importance of the first criterion \\
\hline $2,4,6,8$ & Interim values reflecting compromise \\
\hline Reciprocities & Case when the second criterion is more important than the first criterion \\
\hline
\end{tabular}

Table 3 - Relative rank of the criteria [15]

\begin{tabular}{||c|c|c|c|c|c|c|c||}
\hline & $\mathrm{K} 1$ & $\mathrm{~K} 2$ & $\mathrm{~K} 3$ & $\mathrm{~K} 4$ & $\mathrm{~K} 5$ & $\mathrm{~K} 6$ & Relative rank \\
\hline \hline $\mathrm{K} 1$ & 1 & 1 & 2 & 2 & 2 & 3 & 0.236 \\
\hline $\mathrm{K} 2$ & 1 & 1 & 2 & 5 & 2 & 4 & 0.295 \\
\hline $\mathrm{K} 3$ & $1 / 2$ & $1 / 2$ & 1 & 2 & 4 & 3 & 0.197 \\
\hline $\mathrm{K} 4$ & $1 / 2$ & $1 / 5$ & $1 / 2$ & 1 & 2 & 2 & 0.110 \\
\hline $\mathrm{K} 5$ & $1 / 2$ & $1 / 2$ & $1 / 4$ & $1 / 2$ & 1 & 4 & 0.108 \\
\hline $\mathrm{K} 6$ & $1 / 3$ & $1 / 4$ & $1 / 3$ & $1 / 2$ & $1 / 4$ & 1 & 0.055 \\
\hline
\end{tabular}

C.I. $=0.075$ 


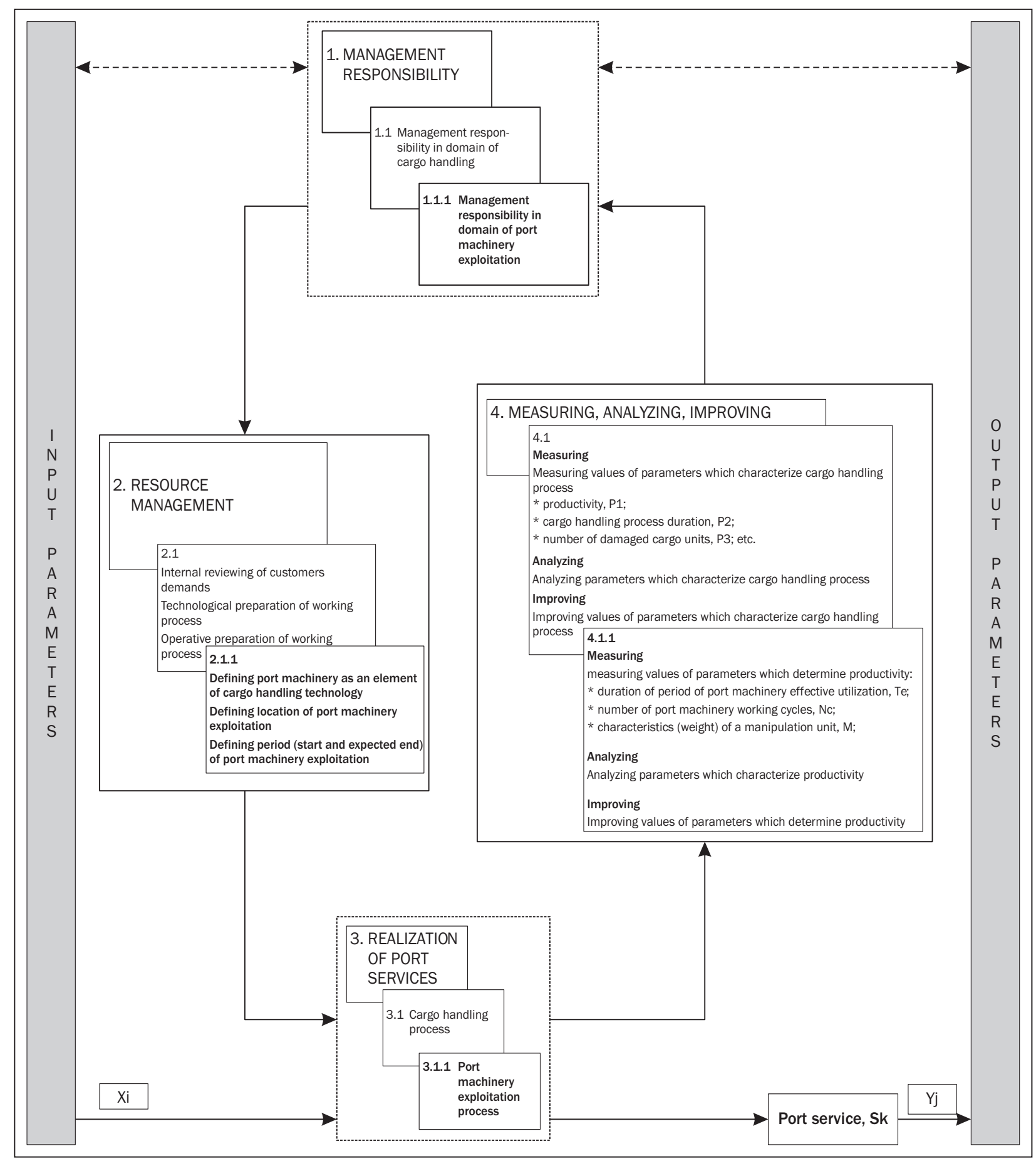

Figure 2 - Model of productivity improving process [17]

Table 4 - Rank of alternatives in relation to all criteria [15]

\begin{tabular}{|c|c|c|c|c|c|c|c||}
\hline \hline Criterion & $\mathrm{K} 1$ & $\mathrm{~K} 2$ & $\mathrm{~K} 3$ & $\mathrm{~K} 4$ & $\mathrm{~K} 5$ & $\mathrm{~K} 6$ & Rank \\
\hline \hline $\begin{array}{c}\text { Weighting } \\
\text { coefficient }\end{array}$ & 0.236 & 0.295 & 0.197 & 0.110 & 0.108 & 0.055 & \\
\hline A1 & 0.085 & 0.025 & 0.021 & 0.022 & 0.030 & 0.008 & 0.191 \\
\hline A2 & 0.047 & 0.084 & 0.101 & 0.040 & 0.017 & 0.024 & 0.312 \\
\hline A3 & 0.019 & 0.018 & 0.014 & 0.007 & 0.008 & 0.004 & 0.071 \\
\hline A4 & 0.085 & 0.168 & 0.062 & 0.041 & 0.052 & 0.019 & 0.426 \\
\hline
\end{tabular}

C.I. $=0.050$ 


\section{Discussion of the results:}

Through the application of AHP method it has been defined that the optimal transformation strategy for the studied port - the Port of Bar (with features presented in Table 1) is the restructuring, and the comparison criterion of the greatest importance is making profit.

The obtained results present the confirmation of hypothesis $\mathrm{H} 1$ - that in line with the characteristics of the Port of Bar the optimal transformation strategy is restructuring. The expected effects of adequately implemented restructuring process are numerous: optimisation of the number of hierarchy levels in the organizational structure, optimization of the range of management in the organizational structure, increase of the utilization level of the available capacities, fulfilment of preconditions for intensifying the investment process (investment maintenance, new capacity building), etc. It is particularly important to directly emphasise that optimal restructuring needs to ensure the following as well:

- fulfilment of the preconditions for concretizing advantages of the Port of Bar: favourable geographical position; existence of significant capacities with the possibility of their further development; existence of specialized terminals, etc.;

- fulfilment of the preconditions for utilization of the Port of Bar opportunities: anticipated general increase of the containers traffic in the east Adriatic ports until 2015; regional initiatives aimed at the establishment of cargo flows through the Port of Bar; modernization of the Bar-Belgrade railway; construction of the Bar-Belgrade highway; increase of transit flows through Montenegro; etc.

\subsection{Character of transformation effects on the productivity level}

In order to illustrate the effects of adequately modelled and realized process of port reform on the productivity in the cargo handling process, Figure 3 presents some data referring to ports in Columbia and Argentina before and after the restructuring process [18]. The level of productivity is quantified through the application of various indicators: for ports in Argentina - tons per employee per annum; for ports in Columbia - tons per vessel per day for dry bulk cargoes and tons per vessel a day for general cargoes.

\subsubsection{Results of the analysis of transformation effects on the productivity in the Port of Bar}

In order to make the basis for the quantification of transformation effects on the productivity level in the studied port - the Port of Bar, the organizational structure has been reviewed before and after the implemented organizational changes (as restructuring process elements) - Figure 4.

Comparing the basic elements of the organizational structures shown in the previous charts, it can be concluded that one of the basic effects of the organizational changes executed through the restructuring process - optimization of the number of employees through outsourcing the additional and supplementary activities (maintenance, security, IT services, ...), consider the definition and implementation of the model for resolving worker redundancy. The effects of the implemented organizational changes may be analyzed from many aspects and quantified in various ways. One way of quantification of the effects of the organizational changes is shown in Figure 5. Based on the handling rate achieved in 2008 [20] and the number of employees prior to and after the restructuring

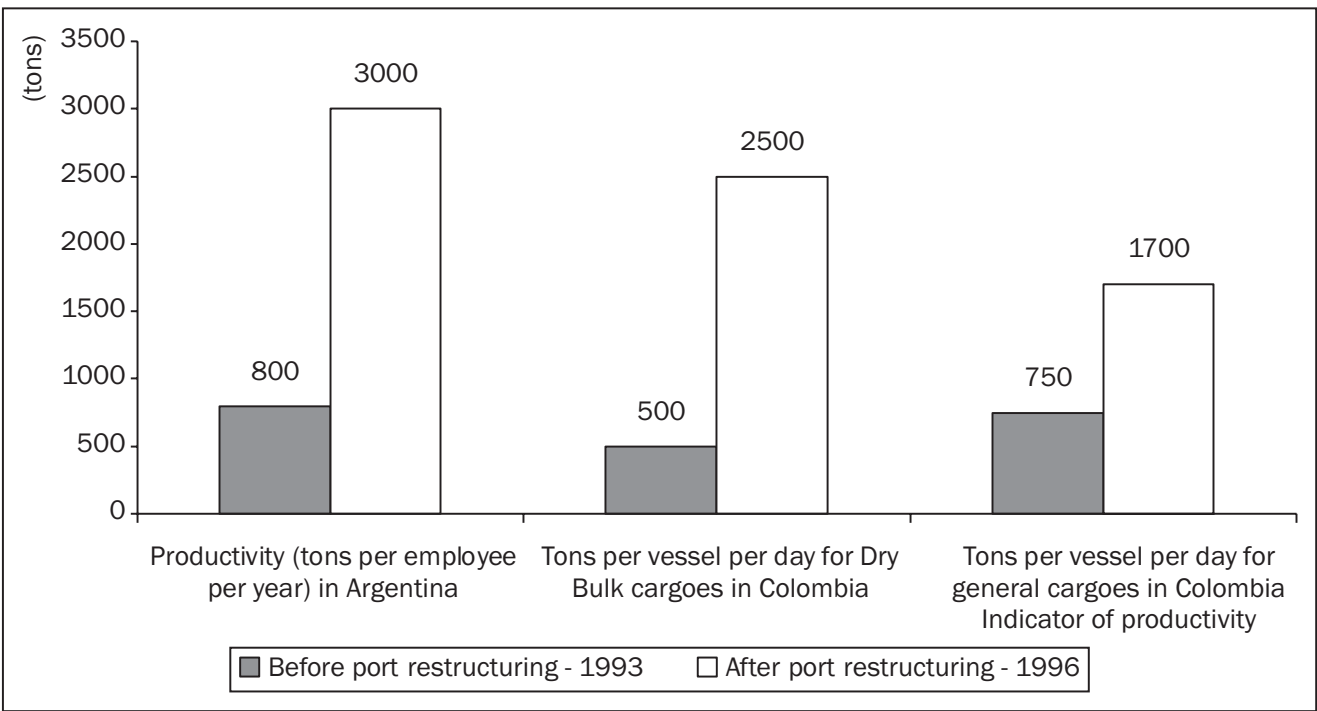

Figure 3 - Indicators of productivity before and after port restructuring [18] 


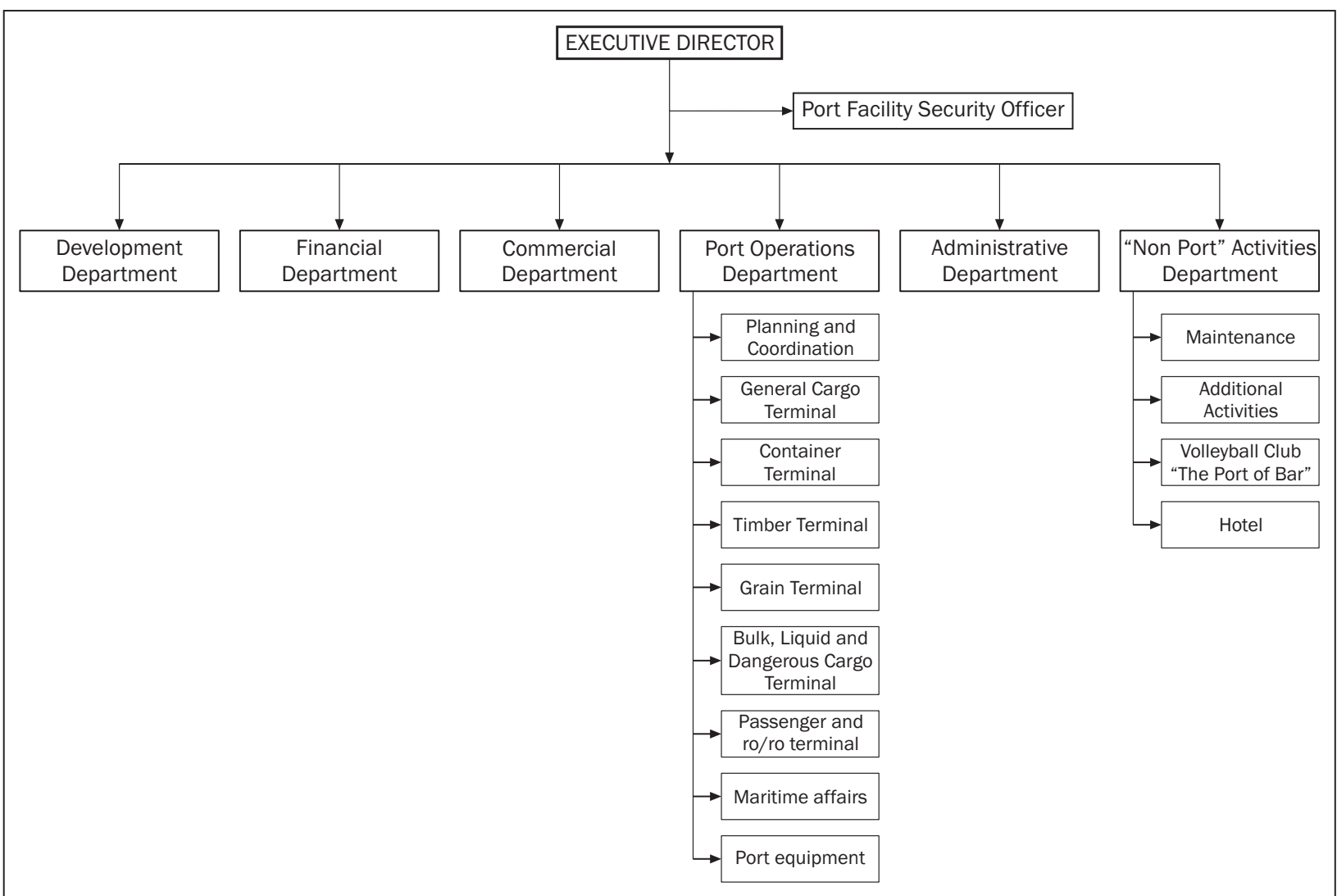

Figure 4a - Organizational structure before the restructuring process [19]

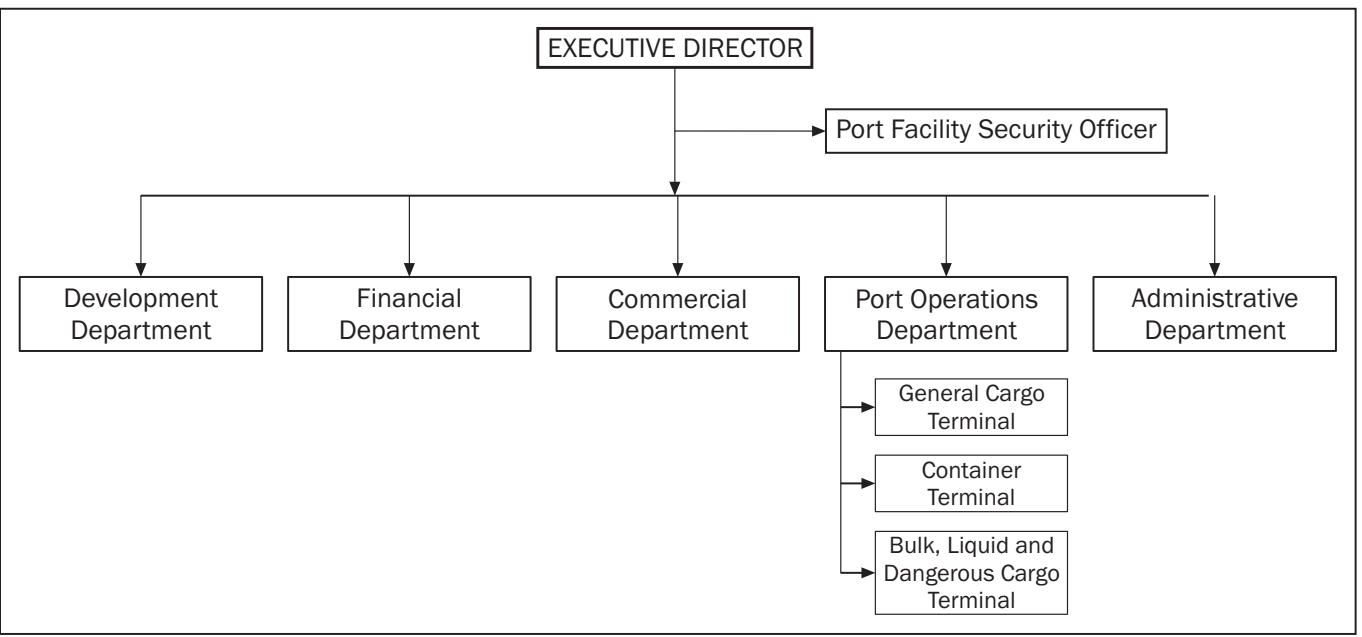

Figure 4b-Organizational structure after the restructuring process [19]

process, the productivity indicator values "ton per employee per year" have been defined, before and after the executed restructuring process.

\section{Discussion of the results:}

The implemented organizational changes, as an element of the restructuring process, have proven their positive outcome by the fact that, based on the optimization of the number of full-time employees, the productivity indicator value "ton per employee per year" is increased by $71 \%$. This implies considerable improve-

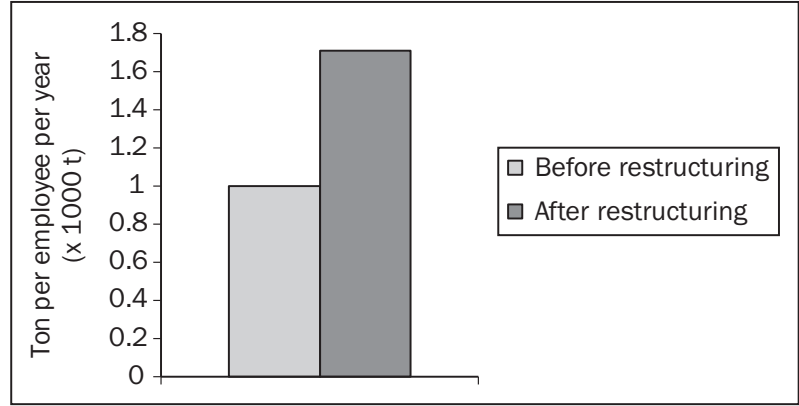

Figure 5 - Quantification of effects of the organizational changes 
ment of income and expenses ratio, which should be fully expressed after fulfilling the preconditions for utilization of advantages and opportunities of the Port of Bar and it should provide gradual rise in the intensity of investment activities (within the domain of improving handling technology, investment maintenance of the port superstructure facilities and similar) to the optimal level. It may be stated that the achieved results are, generally, in conformity with research results related to effects of the restructuring process to the productivity level, which is contained in the available references (for example in the results shown in Figure 3 - for ports in Argentina).

\subsubsection{Correlation between productivity in cargo handling process and ship service time}

In accordance with the results of the previous examinations, it may be stated that one of the objectives of the organizational changes (and restructuring in general) is adequate contribution to the increase of productivity in the handling process (through fulfilling the organizational prerequisites, fulfilling preconditions for optimization of the investment intensity in the domain of the cargo handling technologies etc.).

Productivity improving process is realized through the following basic phases: identifying bases for productivity improving, identifying elements of cargo handling technology where improvements are possible, detailed analysis of identified improving possibilities, realization of improvements. Some of the very important bases of productivity improving process are: cost analyses for previous periods, analyses of technological problems which appeared during the cargo handling process, analyses of available resources (workers, port machinery, lifting accessories ...), etc. The possible domains of productivity improvement are: domain of workers (additional training, specializations...), domain of port machinery (introducing new port machinery with higher efficiency degree, reconstruction and modernisation of existing port machinery ...), domain of lifting accessories (introducing new lifting accessories with better performances ...), domain of infrastructure objects, domain of internal transport flows, etc.

The increasing productivity has positive impact on a very wide range of parameters that characterize execution of the handling process in the port. There is direct correlation between increase in productivity and reduction of ship service time in the port (components of ship service time related to handling operations). The previous statement is concretized by the results of the analysis for the duration of loading/unloading process of a ship with palletized cargo, on ship-warehouse relation in the function of the implemented cargo handling technology variant. The results of the analysis are based on the following input parameters:
- unit quantity of palletized cargo that is transported by ship: $Q_{1}=3000 \mathrm{t}$;

- number of working cycles per hour: $N_{c i}=24 \mathrm{c} / \mathrm{h}$;

- variant 1 of cargo handling technology (basic variant): handling unit, $k_{1}$ - one pallet;

- variant 2 of cargo handling technology (the first level of cargo handling technology improving): handling unit, $k_{2}$ - two pallets;

- variant 3 of cargo handling technology (the second level of cargo handling technology improving): handling unit, $k_{3}$ - four pallets;

- mass of the cargo unit (pallet): $g_{1}=1$ t;

- mass of the handling unit: $m_{i}=k_{i} \times g_{1}$;

- work productivity per hour: $p_{1 i}=N_{c i} \times m_{i}$;

- cargo is located in one ship hold;

- effective working time in one shift: $T_{e}=6 \mathrm{~h}$;

- only one variant of the cargo handling technology is applied during the same shift;

- coefficient $R=Q / Q_{1}(R \in\{0,1,2,3, \ldots, n\})$, where:

$Q$ - total quantity of palletized cargo that is handled during the monitored time interval $T$;

$Q_{1}$ - unit quantity of the palletized cargo;

Implementing the methodology elaborated in [21], which involves the definition of the following parameters: productivity per hour for handling palletized cargo, $P_{1 i}$; calculating time for handling the quantity of cargo $Q_{1}, T_{1 i}$; actual handling time for the quantity of cargo $Q_{1}, T_{s i}$; and so on, the following ratios of real handling times have been obtained implementing different variants of cargo handling technology (Table 5.).

Table 5 - Ratio of real cargo handling times

\begin{tabular}{||c|c||}
\hline $\begin{array}{c}\text { Variants of cargo } \\
\text { handling technology }\end{array}$ & $\begin{array}{c}\text { Characteristic ratios of } \\
\text { real handling times }\end{array}$ \\
\hline \hline $\begin{array}{l}\text { Variant of cargo } \\
\text { handling technology 1 }\end{array}$ & $T_{\mathrm{s} 2} / T_{\mathrm{s} 1}=0.52$ \\
\hline $\begin{array}{l}\text { Variant of cargo } \\
\text { handling technology 2 }\end{array}$ & $T_{\mathrm{s} 3} / T_{\mathrm{s} 1}=0.31 ; T_{\mathrm{s} 3} / T_{\mathrm{s} 2}=0.59$ \\
\hline $\begin{array}{l}\text { Variant of cargo } \\
\text { handling technology 3 }\end{array}$ \\
\hline
\end{tabular}

Based on the previous examinations, graphical dependence is shown (Figure 6) between quantities of

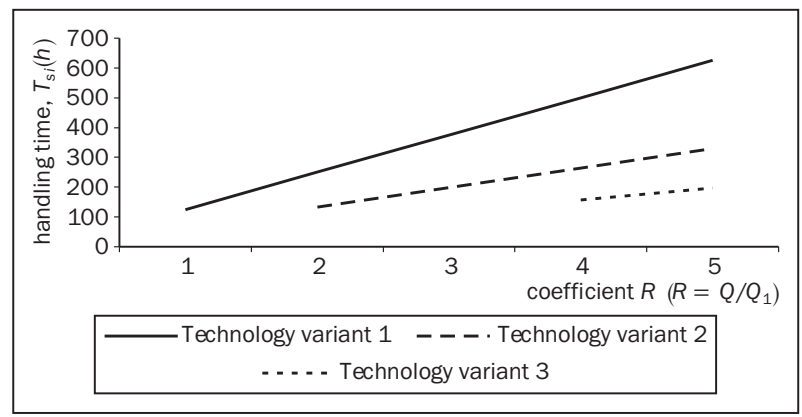

Figure 6 - Correlation among quantity of cargo, handling time and applied cargo handling technology 
cargo that are handled in certain time interval (indicated by value of the coefficient $R$ ) and the real handling time for such cargo quantities in the function of the applied cargo handling technology.

\section{Discussion of the results:}

The obtained results (Table 5 and Figure 6) fully confirm direct correlation between level of productivity of the cargo handling process and time of execution of the handling process. The increasing level of productivity has direct impact on the reduction of ship service time (components of time related to handling operations). By application of the cargo handling technology variant 2 , the real handling time for ship is reduced by $48 \%$, while the implementation of the cargo handling technology variant 3 leads to further reduction of the real handling time for ship (related to the basic variant - reduction of handling time is 69\%).

The results of the analysis specifically indicate the necessity of continuous activities in the domain of improvement of work productivity, primarily through the improvement of cargo handling technology, thus creating the basis for numerous positive impacts on operations of the port as a whole (optimization of utilization rate for available resources, optimization of the income and expenses ratio, contribution to improving market position of the port, contribution to satisfying one of the key requests that transport means should stay in the port as short as possible in connection to the handling operations, ...). In order to enable that such improvements are adequately carried out, appropriate organizational prerequisites must be met, which is achieved by adequately modelled and optimally implemented organizational changes. The results confirm hypothesis $\mathrm{H} 2$ on the existence of direct correlation between organizational changes and level of productivity in the port.

\section{CONCLUSION}

The necessity of continuous adjustment to outcomes of dynamic changes in the port environment and complexity of links of the port with the elements of the mentioned environment generate thr need for implementation of organizational changes in the port. The results of the analysis elaborated in this paper, through the application of AHP (Analytic Hierarchy Process) multi-criteria optimization, have proven that it is optimal to carry out organizational changes within the framework of the restructuring process.

The obtained results confirm one of the starting assumption on the direct correlation between organizational changes and level of productivity in the port. It is especially important, in the context of elaborated examinations, to stress the necessity to fulfil through organizational changes certain preconditions for effi- cient execution of the process of increasing productivity level in the handling process, primarily through improvement of handling technology. This has direct impact on reducing the ship service time in the port (time components related to handling operations), or more precisely, to make the statement more general, it has influence to increasing the level of efficiency of the port as a whole, as a system. The authors have identified many directions for possible further research in the subject matter, and in the first next stage of the engagement, the authors will focus their attention on examining the correlation between the character of organizational changes and parameters of quality of port services.

\section{Dr. SC. DEDA ĐELOVIĆ}

E-mail: deda.djelovic@lukabar.me

Luka Bar

Obala 13. Jula b.b., 85000 Bar, Republika Crna Gora

Mr. Sc. DIJANA MEDENICA MITROVIĆ

E-mail: disan@t-com.me

Fakultet za poslovni menadžment

Maršala Tita br. 7, 85000 Bar, Republika Crna Gora

\section{SAŽETAK}

\section{JEDAN PRISTUP IZBORU OPTIMALNE STRATEGIJE ORGANIZACIONIH PROMJENA U MORSKIM LUKAMA}

Nakon teorijskih razmatranja organizacionih promjena, prikazani su rezultati istraživanja koji se odnose na: izbor optimalnog modela sprovođenja organizacionih promjena u luci koja je predmet analize i utvrđivanje karaktera korelacije između organizacionih promjena, nivoa produktivnosti i vremena opsluživanja broda (komponenti vremena koje se odnose na pretovarne operacije). Primijenjujuću AHP (Analytic Hierarchy Process) metodu, utvrđeno je da je optimalni model realizacije organizacionih promjena u luci koja je objekat istraživanja restrukturiranje. Polazeći od odgovarajućih elemenata procesnog modela unapređenja produktivnosti, identifikovana je direktna zavisnost između karaktera organizacionih promjena i nivoa produktivnosti po stalno zaposlenom radniku $u$ luci, kao i postojanje korelacije između karaktera organizacionih promjena, nivoa produktivnosti u procesu pretovara tereta i vremena opsluživanja broda.

\section{KLUUČNE RIJEČI}

luka, organizacione promjene, AHP metoda

\section{LITERATURE}

[1] Simic, I., (1999.), The role of the management in the process of a company organizational transformation (in Serbian), Economics Faculty, Nis;

[2] Stoner, J. F., Freeman, E., R., Gilbert, D., R., (2000.), Management, Zelnid, Belgrade; 
[3] Jasko, 0., (2000.), Design and management of the organizational changes, Ph.D. thesis (in Serbian), Faculty of the Organizational Science, Belgrade;

[4] Dess, Lumpkin, Eisner, (2007), Strategic Management, 3rd edition (translation in Serbian), Data status, Beograd.

[5] Coulter, M., (2010), Strategic management in practice (translation in Serbian), Data status, Belgrade.

[6] Murphy, R., M., (2003 - a), Managing Strategic Change: An Executive Overview, Unite States Army War College, www.carlisle.army.mil/usawc/dclm/pdf/MurphyMgtText03.pdf;

[7] Murphy, R., M., (2003 -b), Strategic Leadership vs. Strategic Management: Untying the Gordian Knot, United States Army College, www.sba.muohio.edu/ abas/2000/RMurphy.pdf

[8] Stojkovic D., (2006), Models of the specific organization restructuring, Ph.D. thesis, Faculty of Organizational Sciences, Belgrade;

[9] Niekerk, H. (2002), Ports restructuring, policy and regulation: The South African case, IAME Panama 2002, Conference Proceedings, http://www.eclac.cl/ Transporte/;

[10] A.K.C Beresdorf et al.: The UNCTAD and WORKPORT models of port development: evolution or revolution, Maritime Policy and Management, January - March 2004, Vol. 31, No 2, 93 - 107.

[11] Milisavljevic, M., (2000), Strategic management (in Serbian), Cigoja, Belgrade;
[12] Nikolic, I., Bozinovic, S, (2009), Quantitative methods and models in entrepreneurship software WINQSB and EXPERT CHOICE (in Serbian), Faculty for Building Management, Belgrade;

[13] www.expertchoice.com;

[14] Hacker P.T. and Vargas L.G., (1983), Theory of ratio scale estimation: Saaty`s Analytic Hierarchy Process, Management Science, Vol. 33, pp. 1383;

[15] Medenica, D., (2005), A research of seaports transformation models (in Montenegrin), master degree work, Faculty for Traffic Engineering, Belgrade;

[16] * * * (2001), ISO 9001;

[17] Delovic, D.: Productivity in the cargo handling process - some aspects of analysis, $5^{\text {th }}$ International Conference "Research and Development in Mechanical Industry - RaDMI 2005" - Proceedings, Vrnjačka Banja, 2005.

[18] *** (2001), World Bank Port Reform Toolkit www. worldbank.org/html/fpd/transport/;

[19] $* * *$ (2009), Documentation of the Strategic Development Department, the Port of Bar;

[20] *** (2009), Documentation of the Cargo Handling Department, the Port of Bar;

[21] Delovic, D., (2004), Some aspects of correlation between productivity and duration of the cargo handling process, International Conference "Quality Management" Proceedings, Belgrade; 